\title{
A Review of the Metabolic Origins of Milk Fatty Acids
}

\author{
Anamaria COZMA', Doina MIERE ${ }^{1 *}$, Lorena FILIP', Sanda \\ ANDREI ${ }^{2}$, Roxana BANC', Felicia LOGHIN ${ }^{3}$ \\ 1 "Iuliu Hațieganu" University of Medicine and Pharmacy, Faculty of Pharmacy, Department of Environmental \\ Chemistry and Hygiene, 6 Pasteur Street, Cluj-Napoca, Romania; dmiere@umfcluj.ro ('corresponding \\ author),cozma.paraschiva@umfcluj.ro,lfilip@umfcluj.ro,roxana.banc@umfcluj.ro \\ ${ }^{2}$ University of Agronomical Sciences and Veterinary Medicine, Faculty of Veterinary Medicine, Department of \\ Biochemistry and Clinical Laboratory, 3-5 Mănăştur Street, Cluj-Napoca, Romania; sandrei@usamvcluj.ro \\ 3 "Iuliu Hațieganu" University of Medicine and Pharmacy, Faculty of Pharmacy, Department of \\ Toxicology, 6 Pasteur Street, Cluj-Napoca, Romania; floghin@umfcluj.ro
}

\begin{abstract}
Milk fat and its fatty acid profile are important determinants of the technological, sensorial, and nutritional properties of milk and dairy products. The two major processes contributing to the presence of fatty acids in ruminant milk are the mammary lipogenesis and the lipid metabolism in the rumen. Among fatty acids, 4:0 to 12:0, almost all 14:0 and about a half of 16:0 in milk fat derive from de novo synthesis within the mammary gland. De novo synthesis utilizes as precursors acetate and butyrate produced through carbohydrates ruminal fermentation and involves acetyl-CoA carboxylase and fatty acid synthetase as key enzymes. The rest of 16:0 and all of the longchain fatty acids derive from mammary uptake of circulating lipoproteins and nonesterified fatty acids that originate from digestive absorption of lipids and body fat mobilization. Further, long-chain fatty acids as well as medium-chain fatty acids entering the mammary gland can be desaturated via $\Delta-9$ desaturase, an enzyme that acts by adding a cis-9-double bond on the fatty acid chain. Moreover, ruminal biohydrogenation of dietary unsaturated fatty acids results in the formation of numerous fatty acids available for incorporation into milk fat. Ruminal biohydrogenation is performed by rumen microbial population as a means of protection against the toxic effects of polyunsaturated fatty acids. Within the rumen microorganisms, bacteria are principally responsible for ruminal biohydrogenation when compared to protozoa and anaerobic fungi.
\end{abstract}

Keywords: biohydrogenation, fatty acids, lipogenesis, milk

\section{Introduction}

Milk fat is one of the most important components of milk quality, influencing the technological, sensorial, and nutritional properties of milk and dairy products (Cozma et al., 2013). Milk fat consist predominantly of triacylglycerides (TAG) (>95\% of total milk lipids) containing more than 400 individual fatty acids (FA), most of which are present in amounts of $<1 \%$ of total lipids. Only saturated fatty acids of chain lengths from 4 to 18 carbon atoms, cis-9-16:1, cis-9-18:1, trans-18:1, and $18: 3$ n-3 are present in amounts greater than $1 \%$ in milk fat (Jensen $e t$ al., 2002). As numerous in vitro and in vivo studies have shown potential positive effects of milk FA on human health (Shingfield et al., 2008; Mills et al., 2011), it is essential to understand the metabolic origins of FA in milk. Therefore, the aim of this paper was to review the two major processes underlying the origin of FA in ruminant milk: the mammary lipogenesis and the lipid metabolism in the rumen.

\section{Mammary lipogenesis}

Milk FA originate from two sources: the uptake from circulation of preformed FA (ca. 60\%) and de novo synthesis within the mammary gland (ca. 40\%) (Chilliard et al., 2000). Precursors for de novo FA synthesis are acetate and butyrate, volatile FA produced during microbial fermentation of cellulose and hemicellulose in the rumen. Butyrate is converted to $\beta$-hydroxybutyrate in the rumen wall (Jensen, 2002). The mammary gland uses acetate and $\beta$-hydroxybutyrate for the synthesis of 4:0 to 12:0 FA, almost all of myristic acid (14:0) (cca. 95\%) and about a half of palmitic acid (16:0) in milk fat (Shingfield et al., 2013). The rest of 16:0 and all of the long-chain FA (LCFA) derive from mammary uptake of circulating TAG-rich lipoproteins (very low-density lipoproteins and chylomicrons), and plasma albumin bound nonesterified FA (NEFA) that originate from intestinal absorption of lipids and body fat mobilization (Bauman and Griinari, 2003; Shingfield et al., 2010). Mammary lipoprotein lipase allows TAG hydrolysis and NEFA uptake by the mammary 
gland (Chilliard and Ferlay, 2004). Milk fat contains as well odd- and branched-chain FA, which are largely synthesized by rumen bacteria. However, there is evidence that 15:0 and 17:0 secreted in milk are also synthesized de novo from propionate in ruminant tissues, including the mammary gland (Vlaemink et al., 2006).

\section{De novo synthesis}

De novo synthesis of milk FA involves two key enzymes: acetyl-CoA carboxylase and fatty acid synthetase (Chilliard and Ferlay, 2004). Acetate and $\beta$-hydroxybutyrate contribute in an equall manner to the initial unit of four carbon atoms. Acetate is transformed to acetyl-CoA and used for the chain length extension of synthesized FA via the malonyl-CoA pathway, whilst $\beta$-hydroxybutyrate is activated to butyryl-CoA and then incorporated (Shinglfield et al., 2010). Acetyl-CoA carboxylase catalyses the formation of malonyl-CoA from acetate, whereas fatty acid synthetase catalyses the condensation cycles of malonyl-CoA with acetyl-CoA or butyryl-CoA (Chilliard et al., 2000). LCFA containing 16 or more carbon atoms are known to lower mammary FA synthesis in cow or goat mammary epithelial cells in vitro due to direct inhibitory effects on acetyl-CoA carboxylase. The inhibitory effects have shown to be more pronounced when FA contain a longer carbon chain and/or have higher degree of unsaturation (Barber et al., 1997). This phenomenon explains the decrease in the concentrations of medium-chain FA in milk fat following an increase in the supply of LCFA to the mammary gland through diet or body fat mobilization (Chilliard et al., 2000).

\section{Uptake from circulation of preformed $F A$}

In ruminants, FA in milk fats that are taken up from circulation are derived mostly from the digestive absorption of dietary and microbial FA (Bauman and Griinari, 2001). When reaching the intestine, these FA are usually in the unesterified form. They are absorbed in the duodenum, esterified in the enterocyte, and used in conjunction with phospholipids and cholesterol esters in the assembly of very low-density lipoproteins and chylomicrons that pass into the peripheral blood (Vernon and Flint, 1988). Before esterification, stearic acid (18:0) can be desaturated to oleic acid (cis-9-18:1) within the enterocyte, but only to a limited extent (Bickerstaffe et al., 1972). The remainder of the circulating FA originates from the mobilization of body fat reserves, which typically accounts for less than $10 \%$ of milk FA (Shingfield and Griinari, 2007). Nevertheless, the contribution from mobilized FA increases when cows are in early lactation and/or in negative energy balance (Bauman and Griinari, 2003). As 18:0 and cis-918:1 are the main FA stored in ruminant adipose tissue, body fat mobilization induces a sharp increase in these FA concentrations in milk (Chilliard et al., 2003).

\section{$\Delta-9$ desaturation}

LCFA entering the mammary secretory cells can be desaturated, whereas preformed FA cannot undergo elongation (e.g. 16:0 to 18:0) within the mammary gland (Chilliard and Ferlay, 2000). Mammary secretory cells contain the enzyme $\Delta-9$ desaturase that acts by adding a cis9-double bond on the FA chain (Shingfield et al., 2008). $\Delta-9$ desaturase activity in the ruminant mammary gland is assumed to occur as a mechanism to ensure the liquidity of milk for efficient utilization by the offspring (Timmen and Patton, 1988). In this respect, the mammary gland transforms $18: 0$ into $c i s-9-18: 1$ and contributes to $60 \%$ to $80 \%$ of the entire amount of oleic acid secreted in milk (Glasser et al., 2007; Shingfield et al., 2013). Likewise, the activity of $\Delta-9$ desaturase is estimated to contribute to 90\% of cis-9-14:1 and 50\% of cis-9-16:1 in milk fat (Mosley and McGuire, 2007). Other FA shorter than 18 carbon chain length, such as 10:0, 12:0, 14:0, 15:0 and 17:0, can also be used as substrates for $\Delta-9$ desaturase (Shingfield $e t$ al., 2010). Moreover, is estimated that $25 \%$ of the vaccenic acid (trans-11-18:1) formed in the rumen is desaturated in the mammary gland to rumenic acid (cis-9,trans-11-18:2), the main isomer of conjugated linoleic acid in milk (Mosley et al., 2006). Mammary endogenous synthesis from trans-11-18:1 is responsible for $70 \%$ to $95 \%$ of the milk cis-9,trans-11-18:2 (Shingfield et al., 2013).

\section{Triacylglycerides formation}

The above mentioned metabolic pathways (de novo synthesis, uptake from circulation and desaturation) allow the formation of a pool of FA further used to form TAG through glycerol esterification (Chilliard and Ferlay, 2004). The central carbon atom of TAG (sn-2) shows chirality, resulting in an asymmetrical TAG molecule, if two different FA are in the primary positions (sn-1 and sn-3) of the molecule (Kontkanen et al., 2011). The distribution of FA within TAG synthesis is not random. 8:0, 10:0, 12:0 and 14:0 FA are preferentially esterified at sn-2 position, 18:0 is preferentially esterified at sn- 1 position, whereas the distribution of 16:0 between sn- 1 and sn- 2 positions is equal. Short-chain FA (4:0 and 6:0) and cis-9-18:1 are more abundant in the sn-3 position of TAG (Jensen, 2002). FA asymmetrical arrangement on the glycerol molecule, as for example the preferential esterification of short-chain FA and oleic acid on the sn-3 position, has an important influence on the physical properties of milk fat. It decreases milk fat melting point at or below the body temperature of the cow $\left(39^{\circ} \mathrm{C}\right)$, thus ensuring its fluidity (Timmen and Patton, 1988).

\section{Rumen lipid metabolism}

Diets consumed by ruminants generally contain between 20 and $40 \mathrm{~g} \mathrm{lipid} / \mathrm{kg}$ dry matter, with a high proportion of polyunsaturated FA (PUFA) (Shingfield et 
272

al., 2010). The predominant PUFA in ruminant diets are linoleic acid (LA, 18:2 n-6 or cis-9,cis-12-18:2) and linolenic acid (ALA, 18:3 n-3 or cis-9,cis-12,cis-15-18:3), derived from forages, cereals, and oil seeds. Moreover, some oil seeds provide monounsaturated FA (MUFA) (mainly cis-9-18:1), whereas marine products (fish oil, algae) provide long-chain PUFA (mainly 20:5 n-3 (eicosapentaenoic acid, EPA) and 22:6 n-3 (docosahexaenoic acid, DHA)) (Chilliard et al., 2007).

\section{Lipolysis and biohydrogenation of dietary lipids}

On entering the rumen, hydrolysis of the ester linkages found in TAG, phospholipids, and glycolipids is the initial transformation dietary lipids undergo (Lock and Bauman, 2004). Following this lipolysis carried out by lipases produced by rumen bacteria, NEFA are released into the rumen, adsorbed onto feed particles and hydrogenated or incorporated directly into bacterial lipids (Shingfield $e t$ al., 2008). The second major step in dietary lipids metabolism is the ruminal biohydrogenation $(\mathrm{RBH})$ of unsaturated NEFA (Lock and Bauman, 2004). For most diets, RBH averages $80 \%$ for LA and $92 \%$ for ALA (Doreau and Ferlay, 1994). The major pathways of RBH have been established as a result of numerous in vitro and in vivo studies. Metabolism of LA and ALA starts with the isomerization of the cis-12 double bond and the formation of a conjugated 18:2 or 18:3 FA, respectively. Conjugated products are further hydrogenated into trans-11-18:1 and then into 18:0 as the final end product (Harfoot and Hazlewood, 1997). The final hydrogenation phase is rate-limiting, so that trans-18:1 intermediates can accumulate and leave the rumen (Shingfield et al., 2010). RBH of dietary PUFA generates numerous FA intermediates that following formation in the rumen can be incorporated into milk fat (Shingfield et al., 2008). The occurrence of a wide range of isomers of trans-18:1, 18:2 and 18:3 FA containing one or more trans double bonds suggests that the metabolic pathways of $\mathrm{RBH}$ are much complex than previously thought. Therefore, recent studies have been oriented toward the characterization of additional alternative pathways accounting for the formation of specific intermediates during FA biohydrogenation in the rumen (Shingfield et al., 2010).

Regarding the $\mathrm{RBH}$ of cis-9-18:1, this FA is often shown to form directly 18:0 (Jenkins et al., 2008). However, more recent in vitro studies reported that cis-9-18:1 metabolism results in the formation of hydroxystearic (10$\mathrm{OH}$ 18:0) and ketostearic (10-O 18:0) acids and multiple trans-18:1 intermediates with double bond positions from carbon 6 to carbon 16 (Mosley et al., 2002; Jenkins et al., 2006). Cis-9-18:1 RBH typically varies between $58 \%$ and $87 \%$ (Shingfield et al., 2010). Moreover, RBH also occurs on 20- and 22-carbon FA with more than three double bonds, such as EPA and DHA in fish oil and marine algae. The RBH of these FA is ample, but is usually not characterised by a complete saturation (Chilliard et al., 2000).
Incubation of EPA (cis-5,cis-8,cis-11,cis-14,cis-17-20:5) and DHA (cis-4,cis-7,cis-10,cis-13,cis-16,cis-19-22:6) in cultures of mixed ruminal microorganisms led to the disappearance of these two FA as well as to the accumulation of trans-18:1 (AbuGhazaleh and Jenkins, 2004). If consistent with pathways for LA and ALA RBH, the initial isomerization of EPA and DHA should produce isomers with five and six double bonds, including at least one trans double bond. Isomerization should be followed by hydrogenation to isomers with four and five double bonds (Jenkins et al., 2008; Shingfield et al., 2010). However, more research is required to elucidate the biochemical pathways of EPA and DHA metabolism in the rumen.

\section{Microorganisms involved in rumen biohydrogenation}

$\mathrm{RBH}$ involves only some species of the rumen microbial population, carrying out this process as a means of protection against the toxic effects of PUFA on microbial growth (Buccioni et al., 2012). Several studies have shown that within the rumen microorganisms, bacteria are principally responsible for $\mathrm{RBH}$ when compared to protozoa and anaerobic fungi (Jenkins et al., 2008). LA and ALA metabolism involves two groups of ruminal bacteria: Group A, which hydrogenates PUFA to trans-18:1 FA, and Group B, which hydrogenates trans-18:1 FA to 18:0 (Harfoot and Hazlewood, 1997). Nevertheless, more recent studies have reported that cellulolytic bacteria from Butyrivibrio group are of principal importance in $\mathrm{RBH}$. Butyrivibrio fibrisolvens was identified to produce cis9,trans-11-18:2 and trans-11-18:1 from LA, whilst is does not form 18:0 (Jenkins et al., 2008). To the present, the rumen bacteria identified as having the capacity to produce 18:0 are Butyrivibrio hungatei and Clostridium proteoclasticum, reclassified as Butyrivibrio proteoclasticus (Van de Vossenberg and Joblin, 2003; Buccioni et al., 2012). The contribution of protozoa to RBH has been suggested to be due to the activity of ingested or associated bacteria (Jenkins et al., 2008). However, recent data indicate that ruminal protozoal cells contain proportionally more cis9,trans-11-18:2 and trans-11-18:1 than ruminal bacteria. The most likely explanation is that protozoa do not form these FA, but play an important role in the uptake/protection of the intermediates of bacterial $\mathrm{RBH}$ (Devillard $e t$ al., 2006). Moreover, an in vitro study demonstrated that rumen fungi have the capacity to biohydrogenate LA, with Orpinomyces fungus being the most active. $\mathrm{RBH}$ is slower in fungi than in bacteria and has trans-11-18:1 as the end product (Nam and Garnsworthy, 2007).

\section{Conclusions}

In this review, an overview of the most recent studies regarding the metabolic origins of milk FA has been presented. The revision has focused on mammary de novo synthesis, uptake of circulating lipids and $\Delta-9$ desaturation as well as on rumen biohydrogenation as the main processes 
contributing to the presence of FA in ruminant milk. Due to the importance of milk FA in human health, this review intends to be a guide to scientists who start in this challenging area of research.

\section{Acknowledgements}

The authors thank the European Social Fund - project 88/1.5/S/56949 for funding A. Cozma's doctoral research.

\section{References}

AbuGhazaleh AA, Jenkins TC (2004). Disappearance of docosahexaenoic and eicosapentaenoic acids from cultures of mixed ruminal microorganisms. J Dairy Sci 87:645-651.

Barber MC, Clegg RA, Travers MT, Vernon RG (1997). Lipid metabolism in the lactating mammary gland. Biochim Biophys Acta 1347:101-126.

Bauman DE, Griinari JM (2001). Regulation and nutritional manipulation of milk fat: low-fat milk syndrome. Livest Prod Sci 70:15-29.

Bauman DE, Griinari JM (2003). Nutritional regulation of milk fat synthesis. Annu Rev Nutr 23:203-227.

Bickerstaffe R, Noakes DE, Annison EF (1972). Quantitative aspects of fatty acid biohydrogenation, absorption and transfer into milk fat in the lactating goat, with special reference to the cis- and trans-isomers of octadecenoate and linoleate. Biochem J 130:607-617.

Buccioni A, Decandia M, Minieri S, Molle G, Cabiddu A (2012). Lipid metabolism in the rumen: New insights on lipolysis and biohydrogenation with an emphasis on the role of endogenous plant factors. Anim Feed Sci Technol 174:125 .

Chilliard Y, Ferlay A, Mansbridge RM, Doreau M (2000). Ruminant milk fat plasticity: nutritional control of saturated, polyunsaturated, trans and conjugated fatty acids. Ann Zootech 49:181-205.

Chilliard Y, Ferlay A, Rouel J, Lamberet G (2003). A review of nutritional and physiological factors affecting goat milk lipid synthesis and lipolysis. J Dairy Sci 86:1751-1770.

Chilliard Y, Ferlay A (2004). Dietary lipids and forages interactions on cow and goat milk fatty acid composition and sensory properties. Reprod Nutr Dev 44:467-492.

Chilliard Y, Glasser F, Ferlay A, Bernard L, Rouel J, Doreau M (2007). Diet, rumen biohydrogenation and nutritional quality of cow and goat milk fat. Eur J Lipid Sci Tech 109:828 855.

Cozma A, Martin B, Guiadeur M, Pradel P, Tixier E, Ferlay A (2013). Influence of calf presence during milking on yield, composition, fatty acid profile and lipolytic system of milk in Prim'Holstein and Salers cow breeds. Dairy Sci Technol 93:99-113.

Devillard E, McIntosh FM, Newbold CJ, Wallace RJ (2006). Rumen ciliate protozoan contain high concentration of conjugated linoleic acids and vaccenic acid, yet do not hydrogenate linoleic acid or desaturate stearic acid. Brit J Nutr 96:697-704.

Doreau M, Ferlay A (1994). Digestion and utilisation of fatty acids by ruminants. Anim Feed Sci Technol 45:379-396.

Glasser F, Doreau M, Ferlay A, Loor JJ, Chilliard Y (2007). Milk fatty acids: Mammary synthesis could limit transfer from duodenum in cows. Eur J Lipid Sci Technol 109:817-827.

Harfoot CG, Hazlewood GP (1997). Lipid metabolism in the rumen, 382-426 p. In: Hobson PN, Stewart CS (Eds.). The rumen microbial ecosystem. Blackie Academic \& Professional, London, UK.

Jenkins TC, AbuGhazaleh AA, Freeman S, Thies EJ (2006). The production of 10-hydroxystearic acid and 10-ketostearic acids is an alternate route of oleic acid transformation by the ruminal microbiota in cattle. J Nutr 136:926-931.

Jenkins TC, Wallace RJ, Moate PJ, Mosley EE (2008). Recent advances in biohydrogenation of unsaturated fatty acids within the rumen microbial ecosystem. J Anim Sci 86:397412.

Jensen RG (2002). The composition of bovine milk lipids: January 1995 to December 2000. J Dairy Sci 85:295-350.

Kontkanen H, Rokka S, Kemppinen A, Miettinen H, Hellström J, Kruus K, Marnila P, Alatossava T, Korhonen H (2011). Enzymatic and physical modification of milk fat: A review. Int Dairy J 21:3-13.

Lock AL, Bauman DE (2004). Modifying milk fat composition of dairy cows to enhance fatty acids beneficial to human health. Lipids 39(12):1197-1206.

Mills S, Ross RP, Hill C, Fitzgerald GF, Stanton C (2011). Milk intelligence: mining milk for bioactive substances associated with human health. Int Dairy J 21:377-401.

Mosley EE, Powell GL, Riley MB, Jenkins TC (2002). Microbial biohydrogenation of oleic acid to trans isomers in vitro. J Lipid Res 43:290-296.

Mosley EE, Shafii B, Moate PJ, McGuire MA (2006). Cis-9, trans-11 conjugated linoleic acid is synthesized directly from vaccenic acid in lactating dairy cattle. J Nutr 136:570-575.

Mosley EE, McGuire MA (2007). Methodology for the in vivo measurement of the delta9-desaturation of myristic, palmitic, and stearic acids in lactating dairy cattle. Lipids 42:939945.

Nam IS, Garnsworthy PC (2007). Biohydrogenation of linoleic acid by rumen fungi compared with rumen bacteria. J Appl Microbiol 103:551-556.

Shingfield KJ, Griinari JM (2007). Role of biohydrogenation intermediates in milk fat depression. Eur J Lipid Sci Technol 109:799-816.

Shingfield KJ, Chilliard Y, Toivonen V, Kairenius P, Givens DI (2008). Trans fatty acids and bioactive lipids in ruminant milk. Adv Exp Med Biol 606:3-65.

Shingfield KJ, Bernard L, Leroux C, Chilliard Y (2010). Role of trans fatty acids in the nutritional regulation of mammary 
274

lipogenesis in ruminants. Animal 4(7):1140-1166.

Shingfield KJ, Bonnet M, Scollan ND (2013). Recent developments in altering the fatty acid composition of ruminantderived foods. Animal 7:132-162.

Timmen H, Patton S (1988). Milk fat globules: fatty acid composition, size, and in vivo regulation of fat liquidity. Lipids 23:685-689.

Van de Vossenberg JL, Joblin KN (2003). Biohydrogenation of $\mathrm{C} 18$ unsaturated fatty acids to stearic acid by a strain of $\mathrm{Bu}$ tyrivibrio hungatei from the bovine rumen. Lett Appl Microbiol 37:424-428.
Vernon RG, Flint DJ (1988). Lipid metabolism in farm animals. Proc Nutr Soc 47:287-293.

Vlaeminck B, Fievez V, Cabrita ARJ, Fonseca AJM, Dewhurst RJ (2006). Factors affecting odd- and branched-chain fatty acids in milk: A review. Anim Feed Sci Technol 131:389417. 